\title{
A maturidade e o desempenho das equipes no ambiente produtivo
}

\section{Maturity and performance of teams in the production environment}

\author{
Robson Luiz Montanari' \\ Luiz Alberto Pilatti ${ }^{1}$ \\ Isaura Alberton de Lima' \\ Cezar Augusto Romano ${ }^{1}$
}

\begin{abstract}
Resumo: O presente estudo teve como objetivo identificar a influência da maturidade das equipes no desempenho das suas atividades. Para tanto, sete equipes de uma prestadora de serviços foram analisadas. Os procedimentos metodológicos foram permeados por entrevistas, observações não participantes, aplicação de dois questionários e três instrumentos. Os resultados permitiram identificar influências da maturidade no desempenho das equipes em ambiente produtivo, bem como verificar que ela está intimamente relacionada ao comportamento revelado no desempenho dentro do grupo. Nas equipes com maior maturidade, comportamentos indesejáveis ao desempenho coletivo não apareceram na mesma proporção aos das equipes com menor grau de maturidade. Infere-se que, à medida que a maturidade dos grupos é aumentada, pela presença de integrantes mais comprometidos e com confiança mútua, os membros das equipes mudam o comportamento alterando a forma de funcionamento do grupo e transformando-se em uma equipe. Se as equipes em estudo, dentro de uma sequência evolutiva de funcionamento, aumentarem sua maturidade, tendem a influenciar positivamente o seu desempenho no ambiente produtivo em que estão inseridas.

Palavras-chave: Equipes. Maturidade das equipes. Trabalho em equipe. Desempenho de equipes.
\end{abstract}

\begin{abstract}
This study aimed to identify the influence of maturity of the teams in carrying out its activities. Seven teams of a service provider industry were analyzed. The data were collected through interviews, non-participant observations, application of two questionnaires and three instruments. The results showed the influence of maturity on the performance of teams in the production environment and that it is closely related to the individual behavior within the group. In the teams with more maturity, the presence of undesirable collective behaviors did not occur in the same proportion of that of teams with lesser degrees of maturity. It can be inferred that as the maturity of the groups is increased by the presence of more committed members with mutual trust, team members change their behavior by changing the way the group works becoming a team. If the teams under study, within an evolutionary sequence of operation, increase in maturity, this will probably influence positively their performance in the productive environment in which they operate.
\end{abstract}

Keywords: Teams. Teams maturity. Teamwork. Team performance.

\section{Introdução}

Uma ideia equivocada - e que talvez seja justamente a maior razão para o fracasso da formação de equipes - é a crença praticamente universal dos executivos na existência de apenas um tipo de equipe. Essa constatação foi feita por Peter Drucker (2001). Para o autor, existem três tipos de equipes verdadeiras,

[...] cada uma diferente em sua estrutura, no comportamento que exige de seus membros, nas suas forças, vulnerabilidade, limitações e exigências, mas acima de tudo naquilo que pode fazer e que deve ser usada (DRUCKER, 2001, p. 59).
$\mathrm{O}$ autor distingue os três tipos, considerando as diferenças de comportamento exigidas para a sua atuação, isto é, a capacidade inerente para desempenhar o que se faz melhor ou o que não se sabe fazer. Assim, caracteriza os tipos de equipe em: a) aquela cujos membros têm posições fixas: significa que os membros atuam na equipe, mas não em equipe. Como exemplo, pode ser citada uma equipe de beisebol ou uma linha de montagem; b) os membros têm posições fixas, mas atuam em equipe, como, por exemplo, em uma equipe de futebol; e c) os membros têm posições principais em vez de fixas, já que eles devem "cobrir"

\footnotetext{
${ }^{1}$ Programa de Pós-Graduação em Engenharia de Produção - PPGEP, Universidade Tecnológica Federal do Paraná - UTFPR, Campus de Ponta Grossa, Av. Monteiro Lobato, Km 4, CEP 84016-210, Ponta Grossa - PR, E-mails: prof_robson@terra.com.br; lapilatti@utfpr.edu.br; alberton@utfpr.edu.br; caromano@utfpr.edu.br
}

Recebido em 9/4/2009 — Aceito em 9/3/2011

Suporte financeiro: Nenhum. 
seus companheiros de equipe, ajustando-se quando necessário. Um exemplo apontado por Drucker (2001) é o das duplas de tênis.

Em contrapartida, Salomão (1999) considera que o que caracteriza uma equipe são resultados comuns obtidos por interatividade. Ou seja, equipes são identificadas quando pessoas se juntam, oferecem suas competências e conjugam esforços para fazerem coisas que são da responsabilidade do conjunto, mesmo que haja uma "chefia" que se responsabilize pelos membros do grupo. Sacomano Neto e Escrivão Filho (2000, p. 140) mencionam que uma equipe é

[...] um agrupamento de trabalhadores com diferentes responsabilidades funcionais, com objetivos estabelecidos, certa autonomia decisorial e multifuncionalidade dos postos de trabalho.

Algumas percepções sobre grupos e equipes são discutidas por Fisher et al. (1997) e os resultados evidenciam que grupos e equipes são percebidos como ativos, eficazes, energéticos e flexíveis. Entretanto, no que diz respeito às diferenças entre grupos e equipes, as variáveis criativas, inovativas e bons resultados são aplicados somente às equipes. Para Katzenbach (1999, p. 57),

[...] a equipe de verdade segue uma disciplina simples, porém contínua para alcançar bom desempenho. Os membros devem trabalhar juntos para criar produtos de alto valor, e isso requer que o comando seja revezado entre os membros $[\ldots]$.

Na visão de Moscovici (2003, p. 5),

[...] um grupo transforma-se em equipe quando passa a prestar atenção à sua própria forma de operar e procura resolver os problemas que afetam seu funcionamento.

Há conceitos convergentes, como os de Sacomano Neto e Escrivão Filho (2000), Salomão (1999) e Moscovici (2003), os quais relacionam o trabalho em equipe a objetivos comuns, ao compartilhamento de competências e de esforços. No entanto, o fato de trabalharem em conjunto não dá aos grupos, independentemente das posições que seus membros ocupem (fixas ou não), o status de "equipe", contrariando o idear de Drucker (2001), cujo raciocínio proporciona o entendimento de uma situação que nem sempre é suficientemente clara, pois nem todos os grupos têm a mesma finalidade. Em linhas gerais, não existem justificativas para uma equipe de futebol "jogar" como uma dupla de tênis. Na primeira equipe, existe a necessidade de trabalho interdependente, em que os "jogadores" dependem uns dos outros, enquanto na segunda, não. E também não existem justificativas para uma equipe de beisebol "jogar" como uma equipe de futebol, pois na primeira o trabalho é na equipe e não em equipe.

Independentemente da conformação laboral da equipe, o trabalho coletivo é quase sempre involuntário e o comprometimento necessário pode estar ausente, ressalta Bejarano et al. (2005). Na visão de Robbins e Finley (1997, p. 57), o desempenho das equipes está associado às pessoas que, em equipes, são "como as pessoas em qualquer outro lugar", ou seja, "têm seus altos e baixos". Karakowsky et al. (2004) destacaram percepções e influências entre homens e mulheres trabalhando em equipes. Homens e mulheres podem alterar suas percepções na equipe baseando-se, por exemplo, na qualidade de esforços da sua equipe. Em síntese, o desempenho das equipes está relacionado a inúmeros fatores, que são interdependentes no trabalho coletivo. Conduzir equipes na obtenção de melhor desempenho não é tarefa fácil, mesmo quando se podem reunir os melhores talentos individuais.

Não obstante, o emprego tem deslocado o foco de um trabalho individual em um posto específico para o trabalho coletivo. Drucker (2001) aponta que o trabalho em equipe não é bom nem desejável, é um fato. Sempre que as pessoas trabalham em conjunto, elas o fazem em equipe. Para Bejarano (2006), as empresas cada vez mais estão investindo em equipes como parte da sua estrutura organizacional para alcançar melhores índices de produtividade. $\mathrm{Na}$ visão de Claver-Cortés et al. (2007), o cenário é de mudanças e as empresas estão buscando, nas estruturas mais flexíveis, subsídios para atingir patamares competitivos.

Mudanças no atual e moderno ambiente laboral e uma imersão no tema "equipes" são fundamentais diante deste cenário. Bejarano e Pilatti (2008) enfatizam que as literaturas comerciais influenciam as empresas a desenvolverem o trabalho em equipe; na prática, porém, observa-se que pouco se sabe sobre implantar ou utilizar equipes para obter o máximo desempenho conjunto. $\mathrm{O}$ entendimento das relações que envolvem o trabalho em equipe e as diferentes nomenclaturas de equipes no ambiente produtivo pode contribuir no sentido de elucidar a constatação de Drucker (2001) sobre os diferentes tipos de equipes e suas particularidades no funcionamento e no desempenho.

Em se tratando de diferentes tipos de equipes, um fator a considerar é a maturidade. Hersey e Blanchard (1986) e Katzenbach e Smith (1994) fazem uma abordagem sobre maturidade das equipes, relacionando-a com evolução e desempenho. Para Hersey e Blanchard (1986), uma equipe ou uma pessoa passa por diferentes graus de maturidade, não se podendo rotular de equipes ou pessoas de maduras ou imaturas. Katzenbach e Smith (1994) sugerem uma sequência evolutiva no funcionamento de equipes, 
que está intimamente associado à maturidade e ao trabalho que elas desempenham no ambiente produtivo.

Outro fator a considerar, quando o tema é trabalho em equipe, é o resultado desse trabalho, ou seja, o desempenho das equipes no ambiente produtivo. Na visão de Moscovici (2003, p. 21), para algumas empresas, as equipes não produzem melhor do que indivíduos bem capacitados e motivados e

[...] perdem muito tempo em reuniões estéreis, em discussões irrelevantes e em sessões de queixas e lamentações.

No entanto, segundo Aleixo (2003), no atual território empresarial, as equipes têm um papel importante e as reuniões passam a ser fundamentais ao processo de decisão, pois as constantes mudanças e transformações pedem frequentes ajustes às organizações. Para autores como Robbins (2001) e Moscovici (2003), as equipes representam uma ferramenta atual e compatível com as atuais necessidades organizacionais de atender a clientes cada vez mais inconstantes e exigentes, diante do atual e competitivo cenário empresarial.

Considerando-se as equipes como base das mudanças estruturais nas organizações e as indicações de que o trabalho em equipe tem se tornado uma constante e uma realidade nas empresas, o presente estudo tem por objetivo identificar a influência da maturidade da equipe no desempenho das equipes no ambiente produtivo. Para tanto, sete equipes de uma empresa de médio porte, prestadora de serviços, que utiliza a gestão de equipes em seu setor operacional, foram analisadas.

\section{Metodologia}

Para obtenção de conhecimento científico, se faz necessário conhecer as construções mentais que possibilitem alcançar os objetivos almejados. Na visão de Gil (1999, p. 27), isso significa a determinação do método que [...] é o caminho para se chegar a determinado fim. O método de pesquisa utilizado é o estudo de caso que, segundos preceitos de Yin (2001), deve ser utilizado quando uma investigação empírica de um fenômeno dentro de seu contexto da vida real explora as condições entre o fenômeno e o contexto em que este está inserido.

Os procedimentos prescritos por Yin (2001), adaptados ao caso em exame, foram seguidos. Em termos práticos, observam-se as seguintes etapas: a) revisão bibliográfica; b) elaboração de entrevista semiestruturada, composta de questões abertas e com roteiro para sua condução; c) entrevista; d) elaboração de questionários para aplicação aos membros das equipes e aos gerentes; e) definição dos instrumentos para aplicação aos membros das equipes; f) definição da população; g) observações não participantes; h) aplicação dos questionários; i) aplicação dos instrumentos, e j) análise dos dados.

A coleta dos dados aconteceu a partir de quatro entrevistas, aplicação de dois questionários, observações não participantes e aplicação de três instrumentos. Os questionários, elaborados pelos pesquisadores deste estudo, são compostos de questões fechadas. O primeiro, com quatro questões, buscou a percepção das equipes em relação ao seu desempenho no que tange à qualidade dos serviços prestados; o segundo, com três questões, a percepção dos gerentes da empresa em relação ao desempenho das equipes e à qualidade dos serviços prestados por elas.

Os instrumentos são compostos de alternativas e, baseados na experiência de cada membro com sua equipe, o participante escolhe a resposta que melhor reflete seu grau de concordância ou discordância, escolhendo uma nota em uma escala social. O primeiro instrumento trabalha numa escala de 1 a 7 , o segundo de 0 a 7 e o terceiro de 1 a 5. Em relação a cada questão, a nota maior significa "concordo plenamente" e a nota menor, "discordo totalmente".

A coleta dos dados foi efetuada no período de março a agosto de 2007 na empresa em estudo. A população foi composta de um universo de quatro gerentes e 75 membros das equipes existentes. Dois membros de equipe foram descartados, pois estavam participando da primeira reunião em suas equipes e entendeu-se que eles não tinham experiência prática para responder ao questionário e aos instrumentos.

A entrevista semiestruturada foi aplicada a quatro gerentes da empresa. O objetivo da entrevista com um dos entrevistados foi de caráter exploratório; com os demais, o objetivo foi verificar a participação das equipes na qualidade dos serviços prestados pela empresa em estudo. Os entrevistados receberam a sigla D (declarantes) e foram numerados com algarismos arábicos a fim de preservar as suas identidades. Buscando melhorar a interpretação das respostas e dos registros na entrevista, utilizou-se, com a autorização dos entrevistados, um gravador. As gravações foram transcritas ipsis literis, com autorização dos entrevistados.

Na sequência, os questionários e os instrumentos "Avaliação da Reunião" e "O que Acontece no Grupo", propostos por Moscovici (2003), e a "Escala de Maturidade da Equipe" de Dyer (1995), foram aplicados. Juntamente com a aplicação dos instrumentos, foram feitas observações de caráter não participante.

Os membros das equipes responderam ao questionário e aos instrumentos identificando somente a equipe a que pertencem. As equipes receberam a sigla $\mathrm{E}$ (equipe) e foram numeradas com algarismos arábicos. Os gerentes responderam ao questionário sem se identificar. Em seguida, membros de equipes e gerentes depositaram os questionários e instrumentos 
respondidos em urnas a fim de assegurar sigilo sobre suas opiniões e, também, estabelecer um clima de confiança e empatia (TRIVIÑOS, 1987).

Para análise dos dados obtidos, utilizou-se a técnica de triangulação sugerida por Triviños (1987), que, em linhas gerais, consiste no emprego de diferentes evidências para busca de uma resposta mais aprofundada. Segundo Yin (2001, p. 121), [...] várias fontes de evidências fornecem essencialmente várias avaliações do mesmo fenômeno. Os procedimentos tiveram a intenção de aumentar a compreensão dos dados para análise e conclusões dos resultados.

Para análise das entrevistas, foi utilizada a análise de conteúdo que, segundo Minayo (2004), busca encontrar respostas para confirmar as hipóteses. Para tanto, foram organizadas as entrevistas por categorias de acordo com o referencial teórico para facilitar os processos de triangulação dos dados.

Os questionários receberam análise estatística. Os dois primeiros instrumentos receberam análise estatística, na qual, para cada um dos fatores, foi calculada a média aritmética simples e o desvio padrão que caracterizaram o grau de importância médio atribuído a cada fator, a dispersão e a uniformidade de graus atribuídos pelos respondentes.

Para o instrumento de Dyer (1995), a soma das notas individuais $(\mathrm{Mi})$, dividida pelo número de membros da equipe $(\mathrm{N})$, confere a pontuação à equipe, ou seja, o nível de maturidade do grupo $(\mathrm{Mg})$. Após a apuração da maturidade do grupo, foram verificados os parâmetros abaixo para uma avaliação do nível de maturidade da equipe e então identificado na curva de desempenho das equipes de Katzenbach e Smith (1994):

- Pontuação igual ou acima de 3,75: evidencia um nível elevado de maturidade, identificando uma equipe real ou verdadeira. Quanto maior a pontuação, ou seja, mais próxima de 5, maior probabilidade de que a equipe seja uma equipe de alta performance;

- Pontuação entre 2,5 e 3,75 indica um nível intermediário de maturidade, característicos das equipes potenciais e dos grupos de trabalho eficientes; e

- Pontuação inferior a 2,5 indica um nível inadequado de maturidade, o que poderia ser indicativo de uma pseudoequipe ou grupo de trabalho ineficiente.

Após análise dos dados individualmente, estes foram confrontados. Essa confrontação buscou, segundo Yin (2001), as generalizações: as generalizações estatísticas, por meio da inferência sobre a população definida, e as analíticas, pela comparação dos dados empíricos com a teoria.

\section{Especificações do caso}

A empresa em estudo é uma empresa prestadora de serviços, de médio porte, que atua no transporte de passageiros em linhas rodoviárias e metropolitanas no estado do Paraná, em turismo, fretamentos e viagens no Brasil e países do Mercosul, e de logística no estado do Paraná. Atualmente, a empresa possui uma estrutura com cinco filiais, 45 veículos, 100 diferentes pontos de venda no estado do Paraná e aproximadamente 600 colaboradores envolvidos nas atividades diárias da empresa.

O presente estudo limitou-se ao setor operacional, no qual a empresa trabalha com gestão por equipes. As observações não participantes nas reuniões das equipes e a entrevista exploratória permitiram identificar a existência de sete equipes compostas de 11 membros e estruturadas da seguinte forma:

- Um líder, escolhido de forma democrática pelos membros da equipe;

- Um facilitador, determinado pela empresa para auxiliar nas reuniões;

- Missão das equipes;

- Regras de comportamento entre os membros, como: não chegar atrasado às reuniões, participar até o seu término, contribuição nas discussões, evitar conversas paralelas, seja sobre o assunto em questão ou fora dele, ter liberdade de expressão, sem censuras, e somente uma pessoa fala de cada vez; e

- Reuniões periódicas, em média de uma a duas por mês, para o que se definiu uma agenda pelo facilitador e pelos membros das equipes. Regras para as reuniões também foram criadas, como o uso de pauta e o registro em ata das questões levantadas e decisões tomadas.

As sete equipes foram compostas tendo como critério de seleção um balanceamento entre os que já possuíam algumas habilidades necessárias e os que precisavam desenvolvê-las. No trabalho das equipes e nas reuniões, acontece o compartilhamento das informações e experiências vivenciadas no ambiente produtivo. A partir da troca e da discussão dessas informações, os membros das equipes tomam decisões que mudam os processos de trabalho a fim de melhorar a qualidade dos serviços prestados. Em seguida, as equipes registram em atas as alterações sofridas nos processos e as compartilham com as demais equipes para disseminar e auxiliar novos processos de decisões (D1).

\section{A maturidade e o desempenho das equipes no ambiente produtivo}

As experiências pessoais e profissionais têm uma participação fundamental na maturidade das pessoas, 
pois interagem ativamente com a capacidade de cada um em assumir responsabilidades e atuar no estabelecimento de novos comportamentos. À medida que as pessoas mudam o comportamento, adaptam-se a outros novos comportamentos, transformando-se a si mesmos e interagindo com o ambiente produtivo. $\mathrm{O}$ grau de maturidade das pessoas ou equipes de trabalho, em termos gerais, é segundo Hersey e Blanchard (1986) determinante para o desempenho no ambiente produtivo, pois é a partir das experiências vividas, da maturidade que a pessoa tem ou não para desempenhar uma determinada tarefa, que as mudanças podem ser incorporadas a produtos ou serviços.

A maturidade, segundo Hersey e Blanchard (1986), está relacionada com duas dimensões. A primeira com a do trabalho, que está associada à capacidade de fazer algo, uma atividade ou uma tarefa, por exemplo. Refere-se ao conhecimento e à capacidade técnica. As pessoas com alta maturidade de trabalho em uma determinada área têm o conhecimento, a capacidade e a experiência necessária para executarem certas tarefas sem direção da parte de outros. A segunda dimensão está associada à maturidade psicológica, que se refere à disposição ou à motivação para fazer algo. Diz respeito à confiança em si mesmo e ao empenho. As pessoas que têm alta maturidade psicológica em determinada área ou responsabilidade julgam que a responsabilidade é importante, têm confiança em si mesmas, sentem-se bem nesse aspecto do seu trabalho e não precisam de grande encorajamento para cumprir suas tarefas.

Em linhas gerais, o indivíduo com maturidade alta tem disposição para assumir responsabilidades em função da sua capacidade de dirigir seu próprio comportamento. Tal já não ocorre com as pessoas com maturidade baixa. A Figura 1 ilustra a relação apresentada por Hersey e Blanchard (1986), enfatizando a maturidade dos indivíduos ao estilo de liderança.

A liderança situacional de Hersey e Blanchard (1986) baseia-se numa relação entre o comportamento de tarefa e o relacionamento, que, por sua vez, está intimamente associado à maturidade:

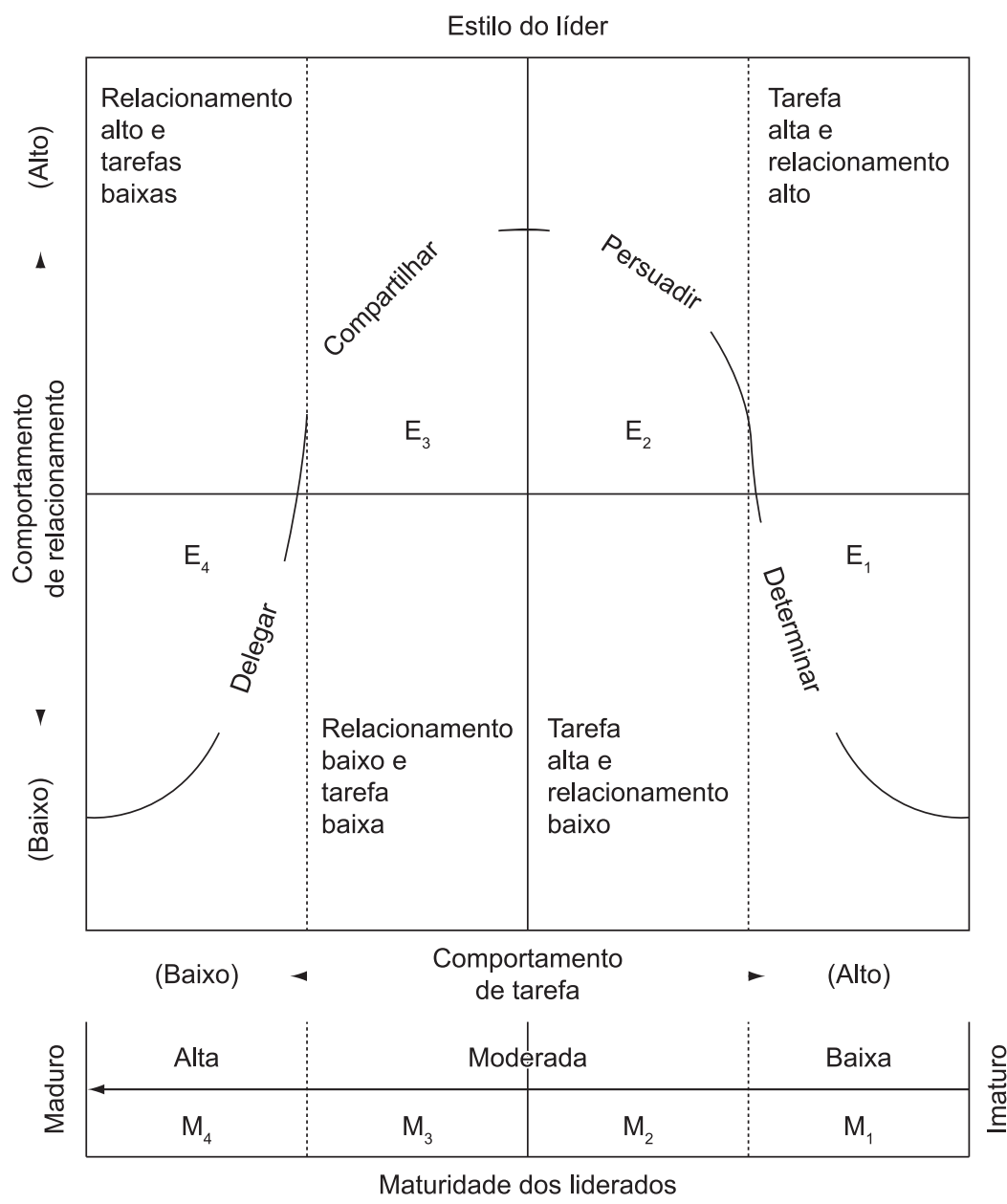

Figura 1. Maturidade dos liderados. Fonte: Hersey e Blanchard (1986, p. 189). 
[...] quanto mais alto o comportamento de tarefa, mais o líder se empenha em planejar, controlar, organizar e dirigir seu subordinado; quanto mais baixo o comportamento de tarefa, mais o líder deixa estas atividades a cargo do subordinado. (SILVA; KOVALESKI, 2006, p. 6).

A Escala de Maturidade de Equipe proposta por Dyer (1995) é um instrumento que, dentro da sequência evolutiva de funcionamento dos grupos, permite identificar na curva de desempenho de Katzenbach e Smith (1994) o tipo provável de equipe, de acordo com sua maturidade. A Figura 2 ilustra a curva de desempenho proposta por esses autores. Na proposta, é evidenciada uma sequência evolutiva de grupos de trabalho até as equipes de alta performance.

Assim como Drucker (2001), Katzenbach e Smith (1994) classificam os grupos de acordo com seu modo de funcionamento e qualificam, segundo o grau de maturidade do grupo, em uma das cinco posições abaixo:

- "Pseudoequipe": este tipo de grupo pode definir um trabalho a ser feito, mas não se preocupa com o desempenho coletivo, nem tenta consegui-lo. As interações dos membros inibem o desempenho individual, sem produzir nenhum ganho coletivo apreciável;

- "Grupo de trabalho": os membros deste grupo não veem nenhuma razão para se transformarem numa equipe. Podem partilhar informações entre si, porém responsabilidades e objetivos, por exemplo, pertencem a cada indivíduo;

- "Equipe potencial": este grupo quer produzir um trabalho conjunto. No entanto, os membros precisam de esclarecimentos e orientações sobre sua finalidade e objetivos;

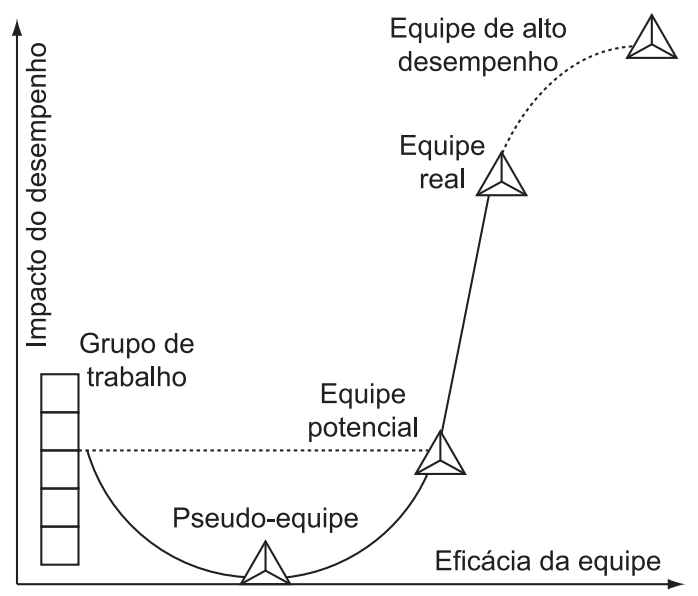

Figura 2. Curva de Desempenho. Fonte: Katzenbach e Smith (1994, p. 85).
- "Equipe real": uma equipe real compõe-se de poucas pessoas, mas com habilidades complementares e comprometidas umas com as outras através de missão e objetivos comuns. Os membros passam a confiar uns nos outros;

- "Equipe de alta performance": este grupo atende a todas as condições de equipe real e tem um comprometimento profundo entre seus membros com o intuito de crescimento pessoal de cada um.

Os resultados obtidos com as equipes em estudo, a partir da aplicação do instrumento de Dyer (1995), evidenciaram, na nomenclatura de Katzenbach e Smith (1994), a existência de uma provável pseudoequipe ou grupo de trabalho, a equipe 3 . As equipes 1, 2, 4 e 5 foram identificadas como prováveis equipes potenciais. Duas equipes (6 e 7) foram identificadas como prováveis equipes reais ou verdadeiras. Esses resultados contrapõem a ideia exposta por Drucker (2001), pois apenas as equipes 6 e 7 são consideradas como equipes verdadeiras na nomenclatura de Katzenbach e Smith (1994). Nessas equipes, segundo os pressupostos desses autores, o nível de maturidade é alto, há confiança e comprometimento entre os membros, além destes possuírem habilidades complementares que contribuirão mais eficazmente no ambiente produtivo.

Na visão de Katzenbach (1999), equipes verdadeiras contribuem agregando valor a produtos e serviços. Este idear é compartilhado por Townsend (1991), Sholtes (1992) e Martins e Laugeni (2001), ao relacionar grupos ou equipes como ferramenta para melhorar e manter a qualidade de produtos ou serviços. Os autores apontam que os membros das equipes trabalham em conjunto, são comprometidos, estabelecem suas metas voltadas ao resultado, a liderança é compartilhada e há soluções de problemas da qualidade. Para melhorar o envolvimento do ambiente produtivo com a qualidade, é são indispensáveis
[..] ações consistentes, na área de recursos humanos, voltadas para o desenvolvimento e treinamento do pessoal bem como o encorajamento ao trabalho em times (MARTINS; LAUGENI, 2001, p. 395).

Nesta mesma linha de pensamento, Moscovici (2003) e Robbins (2001) contextualizam que a interação das pessoas em equipes pode se transformar em um diferencial competitivo importantíssimo ao ambiente empresarial. Para Katzenbach e Smith (2001), as equipes são peças fundamentais para o desempenho empresarial diante de um cenário de mudanças profundas, ou seja, as equipes, o desempenho delas, podem ser utilizadas como resposta às mudanças.

A Tabela 1 sumariza as diferentes percepções das equipes no ambiente produtivo em relação ao seu desempenho e à qualidade dos serviços prestados: 
Observa-se na percepção das equipes 1, 2, 3, 4 e 5 que a existência de reclamações de clientes (item 1) ocorre em menor proporção, quando comparada à percepção das equipes 6 e 7. Essas últimas equipes, em relação à sua percepção quanto à qualidade dos serviços prestados e à contribuição na qualidade dos serviços da empresa (respectivamente, itens 2 e 3 ), apresentam menores médias, caracterizando, em relação às demais equipes, que o desempenho deixa a desejar. E, em relação às mudanças para melhorar a qualidade dos serviços prestados e a prática dessas mudanças (item 4), visualiza-se um quadro em que as equipes 4, 6 e 7 são as que menos acreditam na prática das mudanças sugeridas pelas equipes.

Tomando como base a classificação das equipes em estudo e as percepções das equipes em relação ao desempenho das mesmas (Tabela 1), observa-se que as equipes com maior grau de maturidade (6 e 7) têm percepções que sugerem que elas contribuem em menor proporção para a qualidade dos serviços prestados pela empresa. Resultados divergentes são encontrados nas equipes com maturidade mais baixa $(1,2,3,4$ e 5). Esses resultados são mais bem entendidos nas respostas dos gerentes da empresa ao questionário que avaliou a percepção dos mesmos em relação ao desempenho das equipes e nas entrevistas. Os resultados dos questionários aos gerentes evidenciaram percepções diferentes às das equipes como mostra a Tabela 2.

Os resultados da Tabela 2, em relação aos da Tabela 1 e à classificação das equipes, refletem que as equipes com melhor grau de maturidade (equipes 6 e 7) na percepção dos gerentes são as equipes que melhor contribuem para a qualidade dos serviços prestados pela empresa. Na percepção dos membros dessas equipes, os resultados são divergentes, pois as equipes 6 e 7 têm percepções que sugerem que elas próprias não estão contribuindo significativamente para a qualidade dos serviços prestados pela empresa.

As equipes classificadas com menor maturidade na Escala de Maturidade de Dyer (1995) e identificadas na nomenclatura de Katzenbach e Smith (1994) como provável pseudoequipe e equipe potencial (equipe 3 e 1,2, 4, e 5, respectivamente) tiveram, segundo as percepções de seus membros, melhor desempenho. Para essas equipes, a sua participação na qualidade dos serviços prestados pela empresa em estudo é maior. Em contrapartida, na percepção dos gerentes da empresa (Tabela 2), são as equipes que menos agregam para qualidade dos serviços prestados na empresa. Seguindo os pressupostos teóricos de Katzenbach e Smith (1994) a respeito do desempenho de equipes,

Tabela 1. Percepções das equipes vs. desempenho.

\begin{tabular}{|c|c|c|c|c|c|c|c|}
\hline $\begin{array}{l}\text { Percepções das equipes } \\
\text { vs. }\end{array}$ & $\begin{array}{c}\text { Equipe } \\
1\end{array}$ & $\begin{array}{l}\text { Equipe } \\
\quad 2\end{array}$ & $\underset{3}{\text { Equipe }}$ & $\begin{array}{l}\text { Equipe } \\
4\end{array}$ & $\underset{5}{\text { Equipe }}$ & $\begin{array}{l}\text { Equipe } \\
6\end{array}$ & $\begin{array}{c}\text { Equipe } \\
7\end{array}$ \\
\hline desempenho & \multicolumn{7}{|c|}{$\%$ Respostas positivas } \\
\hline $\begin{array}{l}\text { 1) Existência de reclamações de clientes em } \\
\text { relação aos serviços prestados pelas equipes }\end{array}$ & 63.64 & 81.82 & 88.89 & 81.82 & 72.73 & 100.00 & 90.91 \\
\hline $\begin{array}{l}\text { 2) A qualidade dos serviços prestados pela } \\
\text { equipe no ambiente produtivo }\end{array}$ & 81.82 & 90.91 & 100.00 & 100.00 & 90.91 & 72.73 & 63.64 \\
\hline $\begin{array}{l}\text { 3) } \mathrm{O} \text { trabalho em equipe e a contribuição para } \\
\text { a qualidade dos serviços da empresa }\end{array}$ & 100.00 & 90.91 & 100.00 & 100.00 & 90.91 & 72.73 & 72.73 \\
\hline $\begin{array}{l}\text { 4) Mudanças para melhorar a qualidade dos } \\
\text { serviços prestados e a prática destas }\end{array}$ & 81.82 & 90.91 & 88.89 & 72.73 & 90.91 & 72.73 & 72.73 \\
\hline Média por equipe & 81.83 & 88.64 & 94.44 & 88.64 & 86.36 & 79.55 & 75.00 \\
\hline
\end{tabular}

Fonte: os autores.

Tabela 2. Percepções dos gerentes vs. desempenho das equipes.

\begin{tabular}{|c|c|c|c|c|c|c|c|}
\hline \multirow{2}{*}{$\begin{array}{c}\text { Percepções dos gerentes } \\
\text { vs. } \\
\text { desempenho das equipes }\end{array}$} & $\begin{array}{l}\text { Equipe } \\
1\end{array}$ & $\begin{array}{l}\text { Equipe } \\
2\end{array}$ & $\begin{array}{l}\text { Equipe } \\
3\end{array}$ & $\begin{array}{c}\text { Equipe } \\
4\end{array}$ & $\begin{array}{l}\text { Equipe } \\
5\end{array}$ & $\begin{array}{l}\text { Equipe } \\
6\end{array}$ & $\begin{array}{c}\text { Equipe } \\
7\end{array}$ \\
\hline & \multicolumn{7}{|c|}{ \% Respostas positivas } \\
\hline $\begin{array}{l}\text { 1) A qualidade dos serviços prestados pela } \\
\text { equipe no ambiente produtivo }\end{array}$ & 66.67 & 33.33 & 66.67 & 66.67 & 100.00 & 100.00 & 66.67 \\
\hline $\begin{array}{l}\text { 2) O trabalho da equipe e a contribuição } \\
\text { para a qualidade dos serviços da empresa }\end{array}$ & 66.67 & 66.67 & 66.67 & 66.67 & 66.67 & 100.00 & 100.00 \\
\hline $\begin{array}{l}\text { 3) Mudanças para melhorar a qualidade } \\
\text { dos serviços prestados e a prática dessas }\end{array}$ & 100.00 & 66.67 & 33.33 & 66.67 & 66.67 & 100.00 & 100.00 \\
\hline Média por equipe & 77.78 & 55.56 & 55.56 & 66.67 & 77.78 & 100.00 & 88.89 \\
\hline
\end{tabular}

Fonte: os autores. 
observa-se que o baixo desempenho das equipes é influenciado pelas dificuldades nas interações do grupo e pela falta de orientações nas atividades.

As diferentes percepções dos membros das equipes estão associadas às diferentes maturidades dos próprios membros e das equipes a que pertencem. Para Hersey e Blanchard (1986), baixa ou moderada maturidade são comuns em pessoas que não têm capacidade e que podem ou não sentir vontade de assumir a responsabilidade de fazer algo. Nesse sentido, as equipes com baixa maturidade $(1,2,3,4$ e 5) ainda não estão prestando atenção na sua forma de trabalhar e resolver os problemas, o que afeta seu funcionamento e a impede de transformar-se em uma equipe, como cita Moscovici (2003).

As entrevistas mostraram o quanto os gerentes da empresa confiam no trabalho das equipes para melhorar a qualidade dos serviços prestados. Nas respostas do declarante D2, denota-se melhor essa percepção: "Olha. O que se tem notado realmente é que há usuários que realmente já estão 'até parabenizado' pelas atitudes dos funcionários, acredito então que está surgindo algum efeito sobre isso". Para o declarante D4, "No momento alguma coisa [...] já apareceu, mas lógico com o tempo é que com certeza vai melhorar essa situação". Contudo, nota-se também que existem problemas que podem prejudicar a qualidade dos serviços prestados, como mostram os fragmentos abaixo:

"[...] a gente vê ainda muita falha no pessoal, mas "ta, devagarinho ta indo"” (D2).

“[...] 'ta' sendo colocado em prática, mas têm ainda algumas que não ‘tão' sendo colocadas, às vezes por negligencia ou por falta de vontade deles [...]" (D3).

"Acho que cai bastante também, um pouco, no esquecimento, acredito que acompanhá-lo mais de perto para que isto seja feito" (D4).

As respostas demonstram, em temos gerais, que as equipes apresentam problemas, mas que estes tendem a desaparecer quando o nível de maturidade aumenta. Para o declarante D3, a maioria das decisões, que estão sendo tomadas no trabalho em equipe, está sendo colocadas em prática e isso é um fator positivo. Sacomano Neto e Escrivão Filho (2000), Salomão (1999) e Moscovici (2003) enfatizam que as equipes devem contemplar objetivos comuns ao

Tabela 3. Avaliação da reunião.

\begin{tabular}{|c|c|c|c|c|c|c|c|c|}
\hline \multirow[t]{2}{*}{ Avaliação da reunião } & \multirow[t]{2}{*}{$\begin{array}{l}\text { Escala } \\
\text { Likert }\end{array}$} & $\begin{array}{l}\text { Equipe } \\
1\end{array}$ & $\begin{array}{l}\text { Equipe } \\
2\end{array}$ & $\begin{array}{c}\text { Equipe } \\
3\end{array}$ & $\begin{array}{c}\text { Equipe } \\
4\end{array}$ & $\begin{array}{c}\text { Equipe } \\
5\end{array}$ & $\begin{array}{l}\text { Equipe } \\
6\end{array}$ & $\begin{array}{c}\text { Equipe } \\
7\end{array}$ \\
\hline & & \multicolumn{7}{|c|}{ Notas e desvio padrão } \\
\hline $\begin{array}{l}\text { 1) Suas opiniões foram } \\
\text { solicitadas e/ou levadas } \\
\text { em consideração }\end{array}$ & $\begin{array}{l}\text { 1) Nunca } \\
\text { 7) Sempre }\end{array}$ & 6.18 & 6.36 & 5.82 & 6.73 & 6.00 & 6.64 & 6.64 \\
\hline Desvio Padrão & & 0.751 & 0.674 & 0.782 & 0.467 & 0.447 & 0.505 & 0.505 \\
\hline $\begin{array}{l}\text { 2) A quantidade de sua } \\
\text { participação foi }\end{array}$ & $\begin{array}{l}\text { 1) Insatisfatória } \\
\text { 7) Satisfatória }\end{array}$ & 6.36 & 6.55 & 6.00 & 6.27 & 6.27 & 6.36 & 6.55 \\
\hline Desvio Padrão & & 0.674 & 0.522 & 0.500 & 0.647 & 0.647 & 0.505 & 0.522 \\
\hline $\begin{array}{l}\text { 3) Sua possibilidade } \\
\text { de influenciar nos } \\
\text { resultados foi }\end{array}$ & $\begin{array}{l}\text { 1) Nenhuma } \\
\text { 7) Significativa }\end{array}$ & 6.55 & 6.45 & 6.22 & 6.45 & 6.45 & 6.45 & 6.45 \\
\hline Desvio Padrão & & 0.688 & 0.522 & 0.667 & 0.688 & 0.688 & 0.522 & 0.522 \\
\hline $\begin{array}{l}\text { 4) Em relação à decisão } \\
\text { final você se acha }\end{array}$ & $\begin{array}{l}\text { 1) Sem responsabilidade } \\
\text { 7) Responsável }\end{array}$ & 6.45 & 6.36 & 6.00 & 6.55 & 6.73 & 6.55 & 6.64 \\
\hline Desvio Padrão & & 0.688 & 0.674 & 1.936 & 0.688 & 0.467 & 0.688 & 0.674 \\
\hline $\begin{array}{l}\text { 5) Em relação à reunião } \\
\text { você se sentiu }\end{array}$ & $\begin{array}{l}\text { 1) Frustrado } \\
\text { 7) Satisfeito }\end{array}$ & 6.27 & 5.91 & 5.78 & 6.55 & 6.55 & 6.73 & 6.45 \\
\hline Desvio Padrão & & 0.905 & 0.831 & 1.481 & 0.522 & 0.522 & 0.467 & 0.522 \\
\hline $\begin{array}{l}\text { 6) Você se sente } \\
\text { disposto a defender a } \\
\text { decisão tomada }\end{array}$ & $\begin{array}{l}\text { 1) De maneira nenhuma } \\
\text { 7) Irrestritamente }\end{array}$ & 6.36 & 6.64 & 6.33 & 6.64 & 6.55 & 6.73 & 6.82 \\
\hline Desvio Padrão & & 0.809 & 0.809 & 1.414 & 0.674 & 0.522 & 0.647 & 0.405 \\
\hline $\begin{array}{l}\text { 7) Quanto à qualidade } \\
\text { da decisão tomada você } \\
\text { achou }\end{array}$ & $\begin{array}{l}\text { 1) Péssima } \\
\text { 7) Excelente }\end{array}$ & 6.45 & 6.64 & 5.78 & 6.00 & 6.36 & 6.45 & 6.45 \\
\hline Desvio Padrão & & 0.522 & 0.505 & 0.441 & 0.632 & 0.674 & 0.522 & 0.688 \\
\hline Média por equipe & & 6.37 & 6.41 & 6.00 & 6.45 & 6.41 & 6.55 & 6.57 \\
\hline
\end{tabular}

Fonte: os autores. 
compartilhamento de competências e de esforços para que as metas ou objetivos sejam cumpridos. Para Katzenbach e Smith (1994), o desempenho de equipes com alta maturidade é pautado pelo comprometimento de seus membros em objetivos comuns, o que não se observa nas equipes $1,2,3,4$, e 5 .

Contrariando as percepções dos membros das equipes 1, 2, 3, 4 e 5 e das observações não participantes nas reuniões, estão os resultados obtidos com os instrumentos "Avaliação da Reunião" e "O que Acontece no Grupo". Os resultados demonstram dificuldades nas equipes que estão interferindo no ambiente produtivo. A Tabela 3 sumariza os resultados do questionário "Avaliação da Reunião":

Observa-se na Tabela 3 que as equipes 1, 2, 4, 5 e 6 não apresentam tanta disparidade nos resultados. Porém, a equipe 3 apresenta resultados, em todos os itens, abaixo da média das outras equipes e apresenta o maior desvio padrão nos itens 4, 5 e 6, caracterizando a existência de possíveis problemas e de opiniões divergentes dentro da equipe.

Um fato interessante nos resultados da equipe 3 é o de que, mesmo tendo procedimentos iguais aos das demais equipes durante as reuniões, como constatado com o declarante D1 e nas observações não participantes, esta equipe apresenta resultados divergentes quando comparada às demais equipes. As observações não participantes caracterizaram, nas equipes em estudo, o que é abordado por Parker (1995), Chang (1999) e Katzenbach e Smith (2001) como indispensável às reuniões das equipes: reuniões começando no horário, com pautas e registros das discussões, além de possuírem um moderador ou facilitador para conduzi-las, a fim de evitar as discussões sem sentido. E, no entanto, o desempenho da equipe 3 , na percepção de seus membros, está distante do desejável.

Na visão de Aleixo (2003), sem reuniões, as equipes não sobrevivem, pois são nessas ocasiões que os conflitos e os problemas de comunicação aparecem. São nelas, também, que se oportunizam as trocas de informações, ampliando a comunicação e, consequentemente, se fortalecendo o comprometimento para desenvolver habilidades e preservar a experiência adquirida. Reunião rápida e eficiente não é o objetivo principal; o desejado é o entusiasmo, a criatividade e a participação de todos no processo de solução de problemas em debates abertos, enfatiza Goldbard (1995).

Para Parker (1995), as reuniões eficazes precisam começar no horário, ter um gerenciador para as discussões, com capacidades de estimular as opiniões, esclarecer ideias, sintetizar e não perder o foco no assunto. Chang (1999) ressalta que as reuniões ineficientes apresentam falta de pauta, pouca participação, discussões longas e sem sentido, poucas decisões ou absolutamente nenhuma decisão.
As observações não participantes demonstraram que as reuniões das equipes em estudo começam no horário e têm a presença de um gerenciador; contudo, em inúmeras vezes, observou-se que o assunto em discussão era desviado para outros pontos, acarretando, assim, discussões demoradas e com poucas decisões.

A maneira como a equipe prepara e conduz as reuniões faz uma considerável diferença no ambiente produtivo, menciona Katzenbach e Smith (2001). Diferentes abordagens produzem diferentes comportamentos e, por consequência, resultados distintos. Assim, as equipes devem concentrar muita atenção em dois padrões. O primeiro diz respeito ao uso eficiente do tempo: agendas, assuntos e prazos devem ser definidos com antecedência. O segundo padrão é em relação aos objetivos. Quando não existe um objetivo, as discussões se perdem e raramente decisões são tomadas.

Para Katzenbach e Smith (2001, p. 83), é necessário [...] planejar reuniões e sessões de trabalho que se ajustem a diferentes tarefas e desempenhos obrigatórios. Fazem-se necessárias diferentes reuniões para diferentes tipos de trabalho. Os autores relacionam duas etapas que podem ajudar equipes a planejar e conduzir reuniões mais coerentes para qualquer tarefa a ser realizada. São elas:

Definir o objetivo da reunião em termos de desempenho: as reuniões devem ter objetivos claros diretamente relacionados aos resultados exigidos;

Preparar duas listas de problemas e assuntos: no decorrer das reuniões, pequenos grupos tratam de assuntos diferentes; assim, o desempenho é otimizado.

Essas etapas podem auxiliar no desempenho da equipe, contudo deve-se articular a visão de trabalho à missão da equipe. Para Katzenbach e Smith (2001), as equipes obtêm mais êxito quando discutem as principais influências que pretendem exercer e, quando transformam essas discussões em frases, a equipe ganha um direcionamento melhor no trabalho.

Os resultados da Tabela 3 são complementados com os resultados do questionário "O que Acontece no Grupo" (Tabela 4).

As altas notas nos itens 1 (falta de cooperação), 2 (conspirações e fofocas) e 7 (indiferença em relação ao trabalho) mostram os comportamentos mais frequentes nas equipes. Na equipe 3 , grupo em que os resultados da Tabela 3 refletem a existência de problemas, os resultados nos itens anteriormente citados (Tabela 4) apresentam as maiores notas e os maiores desvios padrão, indicando a divergência de opiniões e a existência de comportamentos que estão prejudicando o desempenho em equipe e o ambiente produtivo, por consequência. Esses resultados refletem o idear de Katzenbach e Smith (1994) a respeito do desempenho: as equipes com menor grau de maturidade apresentam dificuldades de interação e 
Tabela 4. Comportamento nas equipes.

\begin{tabular}{|c|c|c|c|c|c|c|c|}
\hline \multirow[t]{2}{*}{ Comportamentos } & $\begin{array}{c}\text { Equipe } \\
1\end{array}$ & $\begin{array}{c}\text { Equipe } \\
2\end{array}$ & $\begin{array}{c}\text { Equipe } \\
3\end{array}$ & $\begin{array}{c}\text { Equipe } \\
4\end{array}$ & $\begin{array}{c}\text { Equipe } \\
5\end{array}$ & $\begin{array}{c}\text { Equipe } \\
6\end{array}$ & $\begin{array}{c}\text { Equipe } \\
7 \\
\end{array}$ \\
\hline & \multicolumn{7}{|c|}{ Notas e desvio padrão } \\
\hline 1) Falta de Cooperação & 4.82 & 5.00 & 6.11 & 4.09 & 4.09 & 3.91 & 4.27 \\
\hline Desvio Padrão & 0.751 & 0.894 & 1.965 & 0.539 & 0.539 & 0.539 & 0.647 \\
\hline 2) "Conspirações e fofocas" & 3.27 & 3.64 & 5.11 & 3.18 & 3.45 & 3.27 & 3.36 \\
\hline Desvio Padrão & 0.467 & 0.809 & 1.453 & 0.405 & 0.522 & 0.647 & 0.674 \\
\hline 3) Hostilidade entre as pessoas & 0.55 & 0.82 & 0.89 & 0.73 & 0.73 & 0.82 & 1.00 \\
\hline Desvio Padrão & 0.522 & 0.751 & 0.782 & 0.467 & 0.467 & 0.405 & 0.447 \\
\hline 4) Disputa de liderança & 0.27 & 0.45 & 1.00 & 0.45 & 0.55 & 0.64 & 0.64 \\
\hline Desvio Padrão & 0.467 & 0.688 & 0.500 & 0.522 & 0.522 & 0.505 & 0.505 \\
\hline 5) Pessoas tensas e ansiosas & 0.64 & 0.55 & 1.11 & 0.73 & 0.64 & 0.64 & 0.45 \\
\hline Desvio Padrão & 0.505 & 0.688 & 0.782 & 0.467 & 0.505 & 0.505 & 0.522 \\
\hline 6) Choques entre as pessoas & 0.45 & 0.82 & 1.22 & 0.45 & 0.64 & 0.64 & 0.55 \\
\hline Desvio Padrão & 0.522 & 0.603 & 0.833 & 0.522 & 0.505 & 0.505 & 0.522 \\
\hline 7) Indiferença em relação ao trabalho & 2.55 & 2.73 & 3.11 & 1.82 & 0.82 & 0.91 & 1.00 \\
\hline Desvio Padrão & 0.934 & 0.467 & 1.364 & 0.874 & 0.603 & 0.701 & 0.775 \\
\hline 8) Alienação dentro do grupo & 0.27 & 0.73 & 0.89 & 0.64 & 0.55 & 0.45 & 0.45 \\
\hline Desvio Padrão & 0.467 & 0.467 & 0.333 & 0.505 & 0.522 & 0.522 & 0.522 \\
\hline 9) Comunicações incompletas, dúbias & 0.73 & 0.82 & 0.89 & 0.82 & 0.73 & 0.82 & 0.64 \\
\hline Desvio Padrão & 0.467 & 0.603 & 0.333 & 0.405 & 0.467 & 0.405 & 0.505 \\
\hline 10) Conflito entre subgrupos & 1.09 & 1.27 & 1.67 & 0.91 & 1.09 & 0.82 & 0.82 \\
\hline Desvio Padrão & 0.701 & 0.786 & 0.866 & 0.539 & 0.539 & 0.603 & 0.603 \\
\hline Média por equipe & 1.14 & 1.68 & 2.18 & 1.38 & 1.32 & 1.29 & 1.31 \\
\hline
\end{tabular}

Fonte: os autores.

necessidade de orientações para desenvolvimento das atividades no grupo.

Em linhas gerais, pode-se inferir que os resultados obtidos na Tabela 3 estão relacionados aos da Tabela 4 e são inversamente proporcionais. A equipe 7, que obteve a melhor média em relação do desempenho (Tabela 3), alcançou uma das melhores médias na Tabela 4, que apresenta os comportamentos presentes na equipe. Os diferentes comportamentos existentes nas equipes em estudo influenciam o desempenho da equipe no ambiente produtivo, pois à medida que 0 desempenho da equipe (média auferida na Tabela 3) aumenta, a presença de comportamentos indesejáveis à performance do grupo diminui (Tabela 4).

Segundo Katzenbach e Smith (2001), a condução do trabalho em equipe, bem como as reuniões, podem produzir diferentes abordagens entre os membros das equipes e influenciar os comportamentos. Na visão de Moscovici (2003), a falta de recursos para atender a todas as necessidades humanas gera conflitos entre os membros. A trajetória de um grupo é seguida de constantes conflitos que acontecem em virtude do crescimento e desenvolvimento do grupo, e as suas consequências poderão ser positivas ou negativas, dependendo do modo como esse grupo é administrado.

A Figura 3 apresenta as médias de classificação das equipes com a Escala de Maturidade de Dyer (1995) e os dados da Tabela 3, respectivamente, expostas na linha de dispersão, evidenciando os resultados acerca da relação da maturidade das equipes com o seu desempenho.

A linha de dispersão - Linear (Maturidade vs. Desempenho) - indica a tendência dos resultados e, comparando aos resultados obtidos (Maturidade vs. Desempenho), pode-se inferir que os resultados estão assim relacionados: aumentando o grau de maturidade da equipe, a média relacionada ao desempenho das equipes (Tabela 3 ) fica mais próxima da desejável. A equipe 6 foi caracterizada pelo seu grau de maturidade como provável equipe real ou verdadeira - segundo a classificação de Katzenbach e Smith (1994) - e destacou-se com uma das melhores médias no questionário que avaliou o desempenho das equipes (Tabela 3 ).

A Figura 4 apresenta as médias de classificação das equipes com a Escala de Maturidade de Dyer (1995) e as da Tabela 4, respectivamente, expostas na linha de dispersão.

Pode-se inferir que os resultados apresentados na Figura 4 (relação maturidade e comportamento) estão relacionados de modo que aumentando o grau de maturidade da equipe, a média relacionada ao comportamento (Tabela 4) fica mais próxima da desejável. À medida que a maturidade da equipe é aumentada, o grupo passa a contar com integrantes comprometidos - influenciados pela missão e pelos 


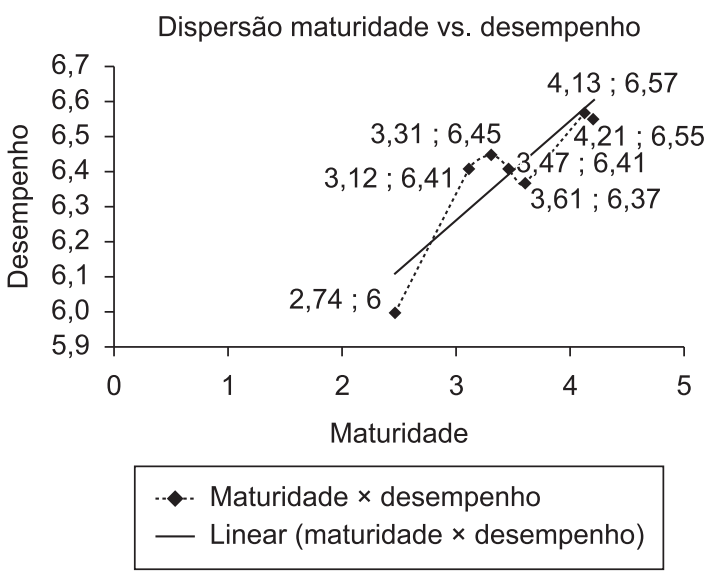

Figura 3. Dispersão da maturidade vs. desempenho das equipes nas reuniões. Fonte: os autores.

objetivos comuns - e passam a confiar uns nos outros, o que contribui significativamente para o desaparecimento de determinados comportamentos, como falta de cooperação, fofocas, disputa pela liderança e outros conflitos relacionados.

As influências da maturidade no desempenho das equipes no ambiente produtivo são caracterizadas pelas diferentes percepções das equipes e dos gerentes da empresa. De um lado, equipes com maior grau de maturidade, as equipes 6 e 7, sugerindo que estas deixam a desejar no que diz respeito ao seu desempenho. E, de outro, gerentes que acreditam que essas equipes são as que apresentam melhor desempenho, que mais contribuem para qualidade dos serviços prestados pela empresa. Embora os membros das equipes com maior maturidade (6 e 7) não concordem que estejam contribuindo efetivamente para qualidade dos serviços prestados, seus gerentes atribuíram a essas equipes o índice de maior contribuição.

Os diferentes desempenhos das equipes em estudo (Tabela 3) e os comportamentos de seus membros no ambiente produtivo (Tabela 4) também caracterizam influências da maturidade no ambiente produtivo. Os resultados estão intimamente relacionados e essa interdependência atua influenciando na maturidade e no desempenho das equipes em estudo.

\section{Conclusões}

Os resultados deste estudo de caso permitiram identificar influências da maturidade no desempenho das equipes no ambiente produtivo. Pode-se inferir que a maturidade das equipes em estudo está intimamente relacionada aos comportamentos presentes (Tabela 4). A relação caracteriza-se de modo que, se as equipes, dentro de uma sequência evolutiva de funcionamento, aumentarem sua maturidade, tendem a influenciar positivamente o ambiente produtivo em que estão

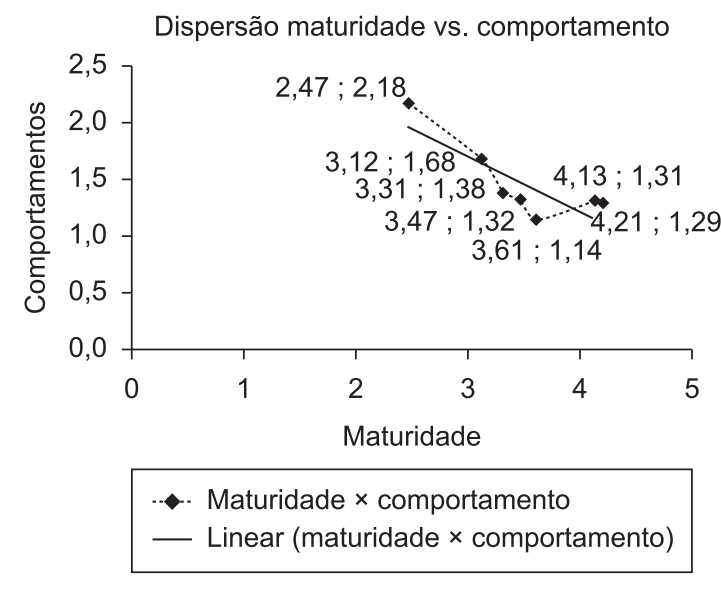

Figura 4. Dispersão da maturidade vs. comportamentos. Fonte: os autores.

inseridas e a melhorar o desempenho no trabalho. As equipes em estudo com elevada maturidade não apresentam, na mesma proporção que as equipes de menor maturidade, comportamentos - falta de cooperação, fofocas, disputa pela liderança e conflitos - que estejam prejudicando o trabalho do grupo e, por consequência, o desempenho.

À medida que a maturidade da equipe é aumentada, através do comprometimento e da confiança entre seus membros, os participantes do grupo tendem a prestar atenção no modo de funcionamento e, como ressalta Moscovici (2003), podem transformar um grupo em uma equipe. Essa relação é justificada pelas diferentes percepções das equipes em relação ao seu próprio desempenho e à qualidade dos serviços prestados pela empresa (Tabela 1). As equipes com maior nível de maturidade acreditam que ainda estão aquém do desempenho que poderiam ter.

Mesmo apresentando características consideradas indispensáveis ao trabalho coletivo, mencionadas por Parker (1995), Chang (1999) e Katzenbach e Smith (2001), as equipes em estudo apresentam características peculiares e individuais que estão condicionadas à sua maturidade. Uma equipe com um nível de maturidade baixo tem diferentes percepções do trabalho coletivo e estas influenciam o funcionamento do grupo. Indiferentemente da nomenclatura das equipes de Drucker (2001) ou Katzenbach e Smith (1994), de seus membros ocuparem posições fixas ou não, a maturidade nas equipes em estudo é determinante e traz influências nas percepções, no comportamento, no modo de funcionamento e nas relações de trabalho das equipes.

O idear de Drucker (2001), segundo o qual todo e qualquer grupo pode ser considerado equipe, é em termos práticos um fato no meio empresarial. Contudo, o atual e moderno ambiente laboral necessita de uma abordagem mais profunda no que tange ao comportamento das pessoas no ambiente produtivo 
em equipe. As equipes se distinguem pelos diferentes graus de maturidade de seus membros, como cita Hersey e Blanchard (1986), e pelas características de funcionamento, apresentadas por Katzenbach e Smith (1994), o que exige de profissionais da área de gestão de pessoas e recursos humanos ferramentas que possibilitem o entendimento dessas relações.

Com os resultados obtidos, pode-se concluir que as equipes em estudo se diferem na sua estrutura e no seu comportamento, como mencionado por Drucker (2001), e no seu funcionamento, como enfatiza Katzenbach e Smith (1994), em função das diferentes maturidades. A maturidade é um fator determinante e incisivo no desempenho das equipes no ambiente produtivo, pois traz influências no trabalho e, por consequência, nos resultados da organização.

\section{Referências}

ALEIXO, A. I. S. Procedimentos para Implantar Equipes. 2003. 111 f. Dissertação (Mestrado em Engenharia da Produção)- Universidade Federal de Santa Catarina, Florianópolis, 2003.

BEJARANO, V. C. et al. Equipes e Comunidades de Prática como Estruturas Complementares na Gestão do Conhecimento Organizacional. In: ENCONTRO NACIONAL DE ENGENHARIA DE PRODUÇÃO, 25., 2005, Porto Alegre. Anais... Porto Alegre: ABEPRO, 2005. p. 4851-4856.

BEJARANO, V. C. Elementos Essenciais à Implementação de Equipes: um estudo de caso da indústria de papel. 2006. 115f. Dissertação (Mestrado em Engenharia da Produção)-Universidade Tecnológica Federal do Paraná, Ponta Grossa, 2006.

BEJARANO, V. C.; PILATTI, L. A. Elementos Externos Essenciais à Implementação de Equipes: estudo de caso. Revista de Administração da Universidade de São Paulo, v. 43, n. 1, p. 17-29, 2008.

CLAVER-CORTÉS, E. et al. Organizational Structure Features Supporting Knowledge Management Processes. Journal of Knowledge Management, v. 11, n. 4, p. 45-57, 2007. http://dx.doi.org/10.1108/13673270710762701

CHANG, R. Y. Construindo uma Equipe de Sucesso. São Paulo: Futura, 1999.

DRUCKER, P. Administrando em Tempos de Grandes Mudanças. 5. ed. São Paulo: Pioneira Thomson Learning, 2001.

DYER, W. Team Building. 3. ed. New York: AddisonWesley Publishing Company Inc, 1995.

FISHER, S. G. et al. Team or Group? Managers' perceptions of the differences. Journal of Managerial Psychology, v. 12, n. 4, p. 232-242, 1997. http://dx.doi. org/10.1108/02683949710174838

GIL, A. C. Métodos e Técnicas de Pesquisa Social. São Paulo: Atlas, 1999.
GOLDBARG, M. A. Times: ferramenta eficaz para a qualidade total. São Paulo: Makron, 1995.

HERSEY, P.; BLANCHARD, K. H. Psicologia para Administradores: as teorias e as técnicas da liderança situacional. São Paulo: EPU, 1986.

KARAKOWSKY, L. et al. Perceptions of Team Performance: the impact of group composition and task-based cues. Journal of Managerial Psychology, v. 19, n. 5, p. 506-525, 2004. http://dx.doi. org/10.1108/02683940410543597

KATZENBACH, J. A Disciplina das Equipes. HSM-Management, n. 17, p. 56-60, 1999.

KATZENBACH, J. R.; SMITH, D. K. A Força e o Poder das Equipes. São Paulo: Makron, 1994.

KATZENBACH, J. R.; SMITH, D. K. Equipes de Alta Performance: conceitos, princípios e técnicas para potencializar o desempenho das equipes. 6 . ed. Rio de Janeiro: Campus, 2001.

MARTINS, P. G.; LAUGENI, F. P. Administração da Produção. São Paulo: Saraiva, 2001.

MINAYO, M. C. S. Pesquisa Social: teoria, método e criatividade. 23. ed. Petrópolis: Editora Vozes, 2004.

MOSCOVICI, F. Equipes dão Certo: a multiplicação do talento humano. 8. ed. Rio de Janeiro: José Olympio, 2003.

PARKER, G. M. O Poder das Equipes. Rio de Janeiro: Campus, 1995.

ROBBINS, S. P. Administração: mudanças e perspectivas. São Paulo: Saraiva, 2001.

ROBBINS, H.; FINLEY, M. Por que as Equipes não Funcionam?. Rio de Janeiro: Campus, 1997.

SACOMANO N. M.; ESCRIVAO FILHO, E. Estrutura organizacional e equipes de trabalho: estudo da mudança organizacional em quatro grandes empresas industriais. Gestão \& Produção, v. 7, n. 2, p. 136-145, 2000. http:// dx.doi.org/10.1590/S0104-530X2000000200004

SALOMÃO, M. A. Desenvolvimento de Equipes. In: BOOG, G. G. [Org.]. Manual de Treinamento e Desenvolvimento. 3. ed. São Paulo: Makron Books, 1999. cap. Desenvolvimento de Equipes, p. 507-532.

SHOLTES, P. R. Times da Qualidade: como usar equipes para melhorar a qualidade. Rio de janeiro: Qualitymark, 1992.

SILVA, U. B.; KOVALESKI, J. Desenvolvimento de Equipe Através da Liderança Situacional e Feedback $360^{\circ}$ - caso de uma equipe de manutenção da Copel Distribuição S.A, Superintendência de Distribuição Centro-sul. In: ENCONTRO NACIONAL DE ENGENHARIA DE PRODUÇÃO, 26., 2006, Fortaleza. Anais... Fortaleza: ABEPRO, 2006. p. 1-9.

TOWNSEND, P. Compromisso com a Qualidade. Rio de janeiro: Campus, 1991.

TRIVINOS, A. Introdução à Pesquisa em Ciências Sociais. São Paulo: Atlas, 1987.

YIN, R. K. Estudo de Caso: planejamento e métodos. 2. ed. Porto Alegre: Bookman, 2001. 